review of the pitfalls of clinical therapeutic trials and an exposition of elementary statistics which seems scarcely recent advances; perhaps in the next edition the authors might leave more of this to the references-so helpfully selective and interspersed throughout the book.

These criticisms are obviously minor; this is the sort of book the clinician has been needing badly for many years and the authors are to be congratulated on its production.

R.F.

\section{A YEAR WITH OSLER: 1896-1897. NOTES TAKEN AT HIS CLINICS IN THE JOHNS HOPKINS HOSPITAL}

By Joseph H. Pratt. Pp. xxi +209 , with 6 illustrations. Baltimore: The Johns Hopkins Press (London: Geoffrey Cumberlege). 1949. $32 s$.

This little volume is a fascinating and valuable contribution to the Osler record.

As a member of the clinical class at the Johns Hopkins Hospital, the author has preserved a verbatim account of a great deal that Osler had to say about the cases he demonstrated to his students more than 50 years ago. On reading this account it is clear that an enthralled and assiduous student at once fell under the spell of a master-mind and a brilliant teacher. These case notes, which are a faithful record of Osler's impromptu pronouncements about patients he had often not seen before, chiefly reveal his astute powers of historical enquiry and clinical observation and his ability to transmit the vital importance of these attributes to his students.

Without X-ray facilities or even the help of blood pressure recording, correct clinical diagnosis and prognosis were frequent. When Osler was proved wrong, however, he eagerly admitted his mistake, using it as a text for an important lesson to be shared and learnt by all.

Osler's profound knowledge of medicine and of men, his literary scholarship and gentle culture make themselves felt throughout this year's instruction, but never are they ostentatious. His intimate knowledge of current literature must have been a spur and stimulus to his students who were constantly encouraged to solve difficult clinical problems by seeking out the truth for themselves.

Few great men in medicine have left behind them a name so noble or so loved as William Osler. Dr. Pratt has offered convincing proof to younger generations that Osler was also a great teacher.

\section{D.S.L.}

\section{THE CYTOLOGY AND LIFE HISTORY OF BACTERIA}

By K. A. Bisset, Ph.D. Pp. xii + r 36, with 43 illustrations. Edinburgh: E. \& S. Livingstone Ltd. 1950. 18s. 6d.
The purpose of this book is to present a reasoned case for regarding bacteria as living cells with the same structure and functions as other living cells. Techniques commonly used in the past, such as drying and heat fixation, have presented a distorted picture of bacteria. Myxobacteria do not stand up to these crude methods and it is only recently that mycologists, applying more refined methods, have been able to demonstrate the nuclear structure and complex life cycle of these organisms. These new techniques have now been used to study bacteria commonly found in the laboratory. Acid hydrolysis as a preliminary to staining and the adaptation of the Feulgen reaction were the first important steps in revealing their nuclei, and the substitution of Giemsa's solution for Schiff's reagent has given a clearer picture of nuclear structures. These appear during the vegetative stage as one or two pairs of chromosomes which split longitudinally during cell division. During the resting stage the paired chromosome-like nucleus of the vegetative cell is transformed into an eccentrically-staining vesicular nucleus by an autogamous or a sexual conjugation. The process of sexual fusion is a normal part of the nuclear cycle of most of the cytologically distinct types of bacteria described; the mechanism is very similar in each case and differs in no essential particular from similar processes in algae, fungi and protozoa. In sporing bacilli a longitudinal rodshaped fusion nucleus is formed from which the ' haploid spore' is derived. In myxobacteria and non-sporing eubacteria the nucleus divides and reconjugates to form the resting nucleus; this nuclear division may be accompanied by division of the cell, in which case the subsequent conjugation will be with other partners and the process a sexual one, or the gametic nuclei may fuse within the original cell; this autogamous process is more common. The author's choice of the term 'microcyst' for the bacterial cell during the resting stage appears to have little justification.

The chapter 'Surface Structures' is so brief as to be misleading. To speak of 'the sensory function' of the cell membrane when so little is known of it and to say that the cell wall of myxobacteria ' is an organ of motility' when its existence can only be inferred is perhaps a little fanciful; also the chapter on ' The Genetics of Bacteria' is presented with more certainty than the evidence would appear to allow.

The proposed classification of bacteria, based on cytology and life history rather than morphology, deserves careful consideration, and of this subject, 'to purchase a clear and warrantable body of truth, we must forget and part with much we know.'

The book is excellently produced and well endowed with bibliographies on each subject. Illustrations are clear but in places their arrangements and spacing could be improved. On the whole it gives a valuable outline of recent important developments in the subject and is recommended.

C.H.L. 